\title{
Isolated Familial Pheochromocytoma as a Variant of von Hippel-Lindau Disease
}

\author{
M. M. RITTER, A. FRILling, P. A. CROSSEY, W. HÖPPNER, E. R. MAHER, \\ L. MULLIGAN*, B. A. J. PONDER, AND D. ENGELHARDT \\ Medical Department II, Klinikum Grosshadern, University of Munich (M.M.R., D.E.), Munich; and the \\ Department of General Surgery, Universitatskrankenhaus Hamburg-Eppendorf (A.F.) and the Institute \\ for Hormone and Fertility Research (W.H.), University of Hamburg, Hamburg, Germany; and the \\ Department of Pathology, Cambridge University (P.A.C., E.R.M.), and the Clinical Research Center for \\ Human Cancer, Genetics Research Group, Addenbrooke's Hospital (L.M., B.A.J.P.), Cambridge, \\ United Kingdom
}

\begin{abstract}
Inherited pheochromocytomas are often part of familial syndromes, especially multiple endocrine neoplasia type 2 (MEN 2), retinal cerebellar hemangioblastomatosis [von Hippel-Lindau (vHL) disease] or neurofibromatosis type 1 . It is not clear whether isolated familial pheochromocytoma exists as a separate clinical entity.

In a family with pheochromocytomas in three generations and with at least seven affected members, we investigated by clinical and genetic analyses the presence or absence of associated conditions. The clinical investigations included ophthalmological and radiological studies for von Hippel-Lindau disease (magnetic resonance imaging of the brain, computed tomography of the abdomen, and direct ophthalmoscopy after mydriasis) and annual calcitonin stimulation tests for $\mathrm{C}$ cell disease in
\end{abstract}

five members who agreed to regular follow-up.

Besides the pheochromocytomas (so far, these have been multiple in five of seven individuals) no definite second associated condition was found. Genetic analysis did not identify any MEN 2-specific RET protooncogene point mutations (which are present in $97 \%$ of MEN 2a families). However, despite the complete absence of other clinical manifestations of the vHL disease (besides pheochromtocytomas), a previously undescribed germline missense mutation in the vHL tumor suppressor gene was found (C775G transversion with a predicted substitution of a leucine by a valine at codon 259 in the putative vHL protein).

We conclude that in this family the sole occurrence of pheochromocytoma is a variant of vHL disease. (J Clin Endocrinol Metab 81: 1035-1037, 1996)
$\mathrm{A}$ PPROXIMATELY $10 \%$ of pheochromocytomas are believed to be inherited (1). Most of them are part of familial syndromes with an autosomal dominant mode of inheritance and other associated conditions, especially multiple endocrine neoplasia type 2 (MEN 2), retinal cerebellar hemangioblastomatosis [von Hippel-Lindau (vHL) disease] and, rarely, neurofibromatosis type 1 . A recent study described the detection of associated familial disease in as many as 19 of 82 patients $(23 \%)$ presenting with pheochromocytoma ( 3 families with MEN 2 and 16 with vHL disease), suggesting an even higher prevalence and clinical importance of familial pheochromocytoma (2).

As all familial pheochromocytoma in the latter study were associated with MEN 2 or vHL disease, the question arises of whether familial pheochromocytoma without other familial conditions exists as an entity. Previously described families $(3,4)$ have not included extensive work-ups (including a calcitonin stimulation test) to rule out the existence of these associated disorders, especially of MEN 2.

Since 1988 we have followed a family ${ }^{1}$ with pheochromocytomas in three generations and with at least seven affected

Received July 10, 1995. Revision received August 31, 1995. Accepted September 21, 1995.

Address all correspondence and requests for reprints to: Dr. Michael M. Ritter, Medical Klinik II, Klinikum Großhadern, University of Munich, 81366 Munich, Germany.

* Present address: Department of Pediatrics, Queen's University, Kingston, Canada.

${ }^{1}$ Before the possibility of vHL genetic analysis, this family was erroneously described as a MEN 2 family (by 2, family 3). members. For reasons stated below, this family was looked upon as a MEN 2 family. Because of the clinical presentation with only adrenal disease, and as total thyroidectomy in the index patient disclosed only a focal presence of $C$ cells but no medullary thyroid carcinoma, we were not convinced of this classification. With the recent availability of genetic diagnosis, we were able to disprove the diagnosis of MEN 2, which has clinical consequences for the family. Furthermore, a new mutation in the vHL disease suppressor gene found in this family demonstrates that the clinical diagnosis of a familial pheochromocytoma-only variant might be a form of the vHL disease.

\section{Subjects and Methods}

\section{Patients}

Since 1988 we have followed a family with pheochromocytomas (the pedigree is given in Fig. 1). The minimal annual examination included a medical history; physical examination; measurement of urinary excretion of vanilmandelic acid, total metanephrines, norepinephrine, and epinephrine; and measurement of serum total calcium concentration and basal and stimulated calcitonin concentrations. With the exceptions stated below, morphological studies were performed in all family members with suspected or proven pheochromocytomas. This included magnetic resonance imaging of the brain, computed tomography of the abdomen, $\left[{ }^{131} \mathrm{I}\right]$ metaiodobenzylguanidine scintigraphy, direct ophthalmoscopy after mydriasis, and ultrasonography of the testes. These studies were performed using standard techniques and with special attention to the manifestations of MEN 2 and vHL disease. All studies were conducted after informed consent had been obtained.

\section{Biochemical analyses}

In 24-h urine collections, epinephrine, norepinephrine, metanephrine, normetanephrine, and vanilmandelic acid were measured, as de- 


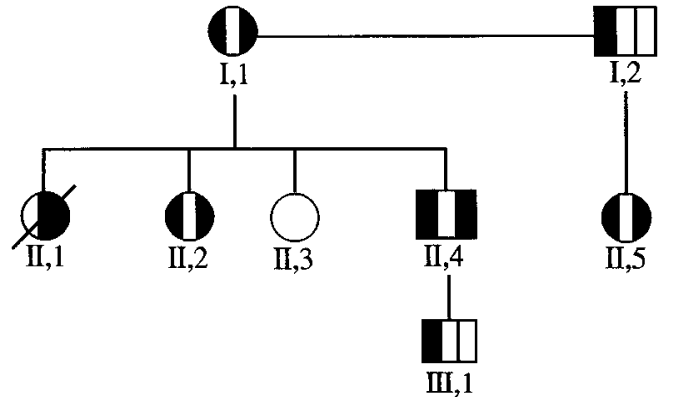

Fig. 1. Pedigree of the investigated family. Circles denote females; squares denote males. The right half of each symbol indicates the presence (solid area) or absence (open area) of left-sided pheochromocytoma (and vice versa); the middle portion denotes extraadrenal pheochromocytoma.

scribed previously (5). Calcitonin stimulation tests were performed by combined stimulation with iv calcium and pentagastrin (6). Measurement of calcitonin was made with an immunoradiometric assay from Medgenix (Fleuris, Belgium). From 1988-1989, the test was considered positive if the stimulated value exceeded $120 \mathrm{pg} / \mathrm{mL}$. In 1990 , we established new reference values (7), and stimulated calcitonin values up to $400 \mathrm{pg} / \mathrm{mL}$ were considered normal.

\section{Genetic analyses}

MEN 2. Genomic DNA was isolated from peripheral leukocytes using an automated DNA extractor, as previously described (8). One hundred nanograms of DNA were PCR amplified for exons 10 (primer CRT 19S and CRT 2C or CRT 19S and CRT 19E9), 11 (CRT 19S and 2C or CRT 19B and $2 \mathrm{C}$ ), and 16 (CRT $5 \mathrm{G}$ and CRT $5 \mathrm{H}$ or F RET 16 and R RET 16). Twenty-five-microliter samples contained $10 \mathrm{mmol} / \mathrm{L}$ Tris- $\mathrm{HCl}$ ( $\mathrm{pH} 8.3$ ), $50 \mathrm{mmol} / \mathrm{L} \mathrm{KCl}, 0.75 \mathrm{mmol} / \mathrm{L} \mathrm{MgCl}_{2}, 0.01 \%$ gelatin, $200 \mu \mathrm{mol} / \mathrm{L}$ deoxyNTPs, and $1 \mathrm{U}$ Taq polymerase with $1 \mu \mathrm{mol} / \mathrm{L}$ each of the appropriate PCR primers. DNA was amplified for 40 cycles of 1 min each at 95, 55, and $72 \mathrm{C}$. PCR products were separated by electrophoresis on $2 \%$ low melting temperature agarose gels and eluted using the Magic PCR Prep system (Promega, Southampton, UK). Purified amplification products were sequenced using the delta Taq cycle sequencing kit (U.S. Biochemical Corp., Cleveland, $\mathrm{OH}$ ). The sequences were resolved on $5 \%$ denaturing polyacrylamide gels.

$v H L$ disease. Screening for $v H L$ gene mutations was performed as described previously. Briefly, the cloned coding sequence of the vHL gene was amplified from genomic DNA using six sets of primer sequences, and each fragment was examined for point mutations by single strand conformational polymorphism analysis (9). The nucleotide sequence of PCR products showing band shifts on single strand conformational polymorphism analysis was determined by direct sequencing with nested primers, using a commercially available cycle sequencing kit (T ife Technologies, Grand Island, NY) according to the manufacturer's guidelines.

\section{Results}

\section{Patients}

With respect to the pedigree shown in Fig. 1, patient I,1 refused clinical investigations, with the exception of an ultrasonography that demonstrated bilateral adrenal tumors but normal renal and thyroid morphology. She also agreed to determination of the basal calcitonin level, which was normal, and a genetic analysis.

Patient II,1 died in childbirth with the symptoms and signs of a hypertensive crisis. Whole body autopsy showed a left adrenal and an extraadrenal pheochromocytoma, but no other features of MEN 2 or vHL disease. The child died 1 day after birth from a cerebral hemorrhage.

Patient II,3 claimed that after performing an ultrasonog- raphy her family doctor had told her that she was not affected by the family disease. She agreed only to the genetic analysis.

All other patients (I,2; II,2; II,4; II,5; and III,1) were screened for MEN 2 and vHL disease. With one exception all results were normal. In patient II,2, two calcitonin stimulation tests were performed, which demonstrated increases from a normal basal value ( 37 and $39 \mathrm{pg} / \mathrm{mL}$ ) to 141 and $295 \mathrm{pg} / \mathrm{mL}$. At that time our upper normal value for calcitonin during the stimulation test was $120 \mathrm{pg} / \mathrm{mL}$, and we considered this increase to be indicative of $\mathrm{C}$ cell hyperplasia. After extensive discussion with the patient, thyroidectomy was performed despite normal ultrasonography of the thyroid. Only a focal presence of $C$ cells, but no medullary thyroid carcinoma, was found. Postoperatively, calcitonin was no longer detectable $(<10 \mathrm{pg} / \mathrm{mL}$ basally and after stimulation).

\section{Genetic analyses}

We were not able to identify any MEN 2A-specific RET point mutations in genomic DNA of the family members tested at codons $609,611,618,620$, and 634 in exons 10 and 11 , respectively. Furthermore, no mutations were found in exon 16 (codon 918).

Examination of the vHL gene identified a $\mathrm{C}$ to $\mathrm{G}$ transversion at nucleotide 775 of the published coding sequence (10). This sequence change was predicted to cause a substitution of a leucine by a valine at codon 259 in the putative vHL protein. The $\mathrm{C} 775 \mathrm{G}$ change segregated with the disease and has not been detected in analysis of more than 400 normal vHL alleles.

\section{Discussion}

We describe a family suffering from familial pheochromocytoma with seven affected subjects in three generations. In the absence of cutaneous manifestations and, therefore, exclusion of neurofibromatosis type 1, we had to differentiate among the diagnoses of MEN 2, retinal cerebellar hemangioblastomatosis, and isolated familial pheochromocytoma.

The diagnosis of MEN 2 appeared unlikely because none of the affected family members (at 14, 20, 29, 42, 45, 59, and $71 \mathrm{yr}$ of age) suffered from overt thyroid disease, and an adequately and repeatedly performed screening for medullary thyroid carcinoma gave normal results in 4 of 5 patients. In 25 patients, members of 5 MEN 2 families, we have found no patient with a pheochromocytoma or primary hyperparathyroidism without $C$ cell disease (unpublished data). However, Gagel et al. (11) described adrenal disease preceding by 5 and 8 yr the detection of $C$ cell abnormalities in 2 of 19 MEN 2 patients with pheochromocytoma. Thus, the detection of adrenal disease as the first manifestation in MEN 2 patients is occasionally possible; however, the absence of thyroid disease $24 \mathrm{yr}$ (patient II,4) and 12 yr (patient II,5) after detecting pheochromocytoma would have been unprecedented.

One patient (II,2) had a calcitonin stimulation test that was considered abnormal. Consequently, thyroidectomy was performed. At that time, we used an upper normal limit for calcitonin during the stimulation test of $120 \mathrm{pg} / \mathrm{mL}$. Subsequently, based on tests in 20 healthy volunteers, we established an upper normal limit for stimulated calcitonin of $400 \mathrm{pg} / \mathrm{mL}$ (7). The histological evaluation in this patient showed only focal $\mathrm{C}$ cell hyperplasia, but no medullary thyroid carcinoma. Focal $\mathrm{C}$ cell 
hyperplasia can represent a normal finding in the thyroids of children less than $6 \mathrm{yr}$ of age and in elderly patients (12). Recently, positive stimulation tests and $\mathrm{C}$ cell hyperplasia in the operated thyroid were described as a normal finding in unaffected members of MEN 2 families (13). Thus, we now judge the calcitonin stimulation test performed preoperatively on patient II,2 as normal and the histological findings as not proven for MEN 2-associated $C$ cell disease.

Mutations in the RET protooncogene were identified as the genetic defect in MEN 2 (14, 15). Based on this experience, genetic analysis of the family was carried out. RET protooncogene mutations in exons 10 and 11 are present in $97 \%$ of MEN 2A families and in $86 \%$ of the patients with familial medullary thyroid carcinoma (16). In almost all MEN 2B patients tested recently, mutations in exon 16 were detectable (17).

We were not able to detect any MEN 2-specific RET protooncogene mutations in exons 10,11, and 16 and concluded that the diagnosis of MEN 2 was extremely unlikely. Therefore, calcitonin stimulation tests were no longer needed in the care of this family.

At about the time of the discovery of the MEN 2 gene, rearrangements in a gene named vHL disease tumor suppressor gene were identified as the causal defect for $\mathrm{vHL}$ disease (10). Therefore, a search for a defect in this gene in the described family was performed. Despite the complete absence of other clinical manifestations, a mutation in the vHL tumor suppressor gene was found.

The positive finding of a mutation in this gene obviates the need for further testing in the RET protooncogene, as additional mutations in $3 \%$ of MEN 2a families were found that do not harbor one of the common mutations in codons 609 , $611,618,620$, and 634 (these showed only the wild-type allele in this family) (18).

The presence of pheochromocytoma in $20 \%$ of vHL families is often used to classify the disease into two types; families without pheochromocytoma are described as vHL type 1, and those with pheochromocytoma as vHL type 2 (19-21). Interesting correlations between this phenotype expression and the types of mutations in the vHL disease tumor suppressor gene have been reported $(9,21)$. In short, missense mutations (in contrast to deletions, insertions, and nonsense mutations) are found significantly more often in families with vHL type 2 .

The family described in this manuscript is the first reported family with a mutation in the $\mathrm{vHL}$ disease tumor suppressor gene, but with pheochromocytoma as the only manifestation of vHL disease (i.e. without angiomas, hemangioblastomas, and renal cell carcinomas). Therefore, the family cannot be assigned to one of the two above-mentioned types of $\mathrm{vHL}$ disease. The C775G mutation detected in this family has not been described previously, but it is interesting to note that it is also a missense mutation. Furthermore, the mutation identified is at the very 3 '-end of the vHL disease tumor suppressor gene, and the substitution of leucine by valine is supposed to cause little conformational change in the putative vHL protein. The absence of other vHL manifestations in all seven members of the family is unlikely to be coincidental given the prevalence and mean age at onset of the other clinical features of the disease (22). Therefore, the association of this particular mutation with such a pheochromocytoma-only variant of vHL disease might contribute to an understanding of the genetic mechanisms of vHL disease.
In conclusion, we have shown that in this family, the sole occurrence of pheochromocytoma is a minor variant of $\mathrm{vHL}$ disease. To emphasize both the relationship to and the distinction from the full blown syndrome, we propose that this pheochromocytoma-only variant be called vHL type 3 .

\section{Note added in proof:}

Since the writing of the manuscript, the numbering of the vHL coding sequence has been changed: codon 259 is now counted as codon 188 (Iliopoulos O, Kibel A, Gray S, Kaelin WG. 1995 Tumor suppression by the human von Hippel-Lindau gene product. Nature Medicine 1: 822-826).

\section{Acknowledgments}

We are indebted to W. Mraz, M.D., and K. Jacob, Ph.D., Institute for Clinical Chemistry at the Klinikum Grosshadern, for determinations of calcitonin and urinary catecholamines.

\section{References}

1. Levine C, Skimming J, Levine E. 1992 Familial pheochromocytomas with unusual associations. J Pediatr Surg. 27:447-451.

2. Neumann HPH, Berger DP, Sigmund G, el al. 1993 Phteochronocytonas, multiple endocrine neoplasia type 2 and von Hippel-Lindau disease. $\mathrm{N}$ Engl J Med. 329:1531-1538.

3. May AG, Moss A, Gutierrez OH, Burday SZ, Campbell RG. 1981 Clinical study of pheochromocytoma. Am J Surg. 141:346-352.

4. Steiner AL, Goodman AD, Powers SR. 1968 Study of a kindred with pheochromocytoma, medillary thyroid carcinoma, hyperparathyroidism and Cushing's disease: multiple endocrine neoplasia, type 2. Medicine. 47:371-409.

5. Jacob K, Vogt W, Schwertfeger G. 1984 Sensitive mass fragmentographic determination of acidic catecholamine metabolites in human body fluids. $J$ Chromatogr. 290:331-337.

6. Wells SA, Baylin SB, Lineham WM, Farrell RE, Cox EB, Cooper CW. 1978 Provocative agents and the diagnosis of medullary carcinoma of the thyroid gland. Ann Surg. 188:139-141.

7. Kempter B, Ritter MM. 1991 Unexpected high calcitonin concentrations after pentagastrin stimulation. Clin Chem. 37:473.

8. Mathew CGP, Chin KS, Easton DF, et al. 1987 A linked genetic marker for multiple endocrine neoplasia type 2A on chromosome 10. Nature. 328:527-528.

9. Crossey PA, Richards FM, Foster K, et al. 1994 Identification of intragenic Inutations in the von Hippel-Lindau disease tumor suppressor gene and correlation with disease phenotype. Hum Mol Genet. 3:1303-1308.

10. Latif F, Tory K, Gnarra J, et al. 1993 Identification of the von Hippel-Lindau disease tumor suppressor gene. Science. 260:1317-1320.

11. Gagel RF, Tashjian AH, Cummings $\mathbf{T}$, et al. 1988 The clinical outcome of prospective screening for multiple endocrine neoplasia type 2a. An 18-year experience. N Engl J Med. 318:478-484.

12. Gibson WGH, Peng T, Croker BP. 1982 Age-associated C-cell hyperplasia in the human thyroid. Am J Pathol. 106:388-393.

13. Lips CJM, Landsvater RM, Höppener JWM, et al. 1994 Clinical screening as compared with DNA analysis in families with multiple endocrine neoplasia type 2A. N Engl J Med. 331:828-835.

14. Donis-Keller $\mathbf{H}$, Dou $\mathrm{S}$, Chi D, et al. 1993 Mutations in the RET protooncogene are associated with MEN 2A and FMTC. Hum Mol Genet. 2:851-856.

15. Mulligan LM, Kwok JBJ, Healey CS, et al. 1993 Germ-line mutations of the RET proto-oncogene in multiple endocrine neoplasia type $2 \mathrm{~A}$. Nature. 363:458-460.

16. Mulligan LM, Eng C, Healey CS, et al. 1994 Specific mutations of the RET proto-oncogene are related to disease phenotype in MEN 2A and FMTC. Nature Genet. 6:70-74.

17. Hofstra RMW, Landsvater RM, Ceccherini I, et al. 1994 A mutation in the REI proto-oncogene associated with multiple endocrine neoplasia type $2 \mathrm{~B}$ and sporadic medullary thyroid carcinoma. Nature. 367:375-376.

18. Eng C, Smith DP, Mulligan LM, et al. 1995 A novel point mutation in the tyrosine kinase domain of the RET proto-oncogene in sporadic medullary thyroid carcinoma and in a family with FMTC. Oncogene. 10:509-513.

19. Glenn GM, Daniel LN, Choyke P, et al. 1991 Von Hippel-Lindau (VHL) disease: distinct phenotypes suggest more than one mutant allele at the VHL locus. Hum Genet. 87:207-210

20. Tisherman SE, Tisherman BG, Tisherman SA, Dunmire $S$, Levey GS Mulvihill JJ. 1993 Three-decade investigation of familial pheochromocytoma? An allele of von Hippel-Lindau disease? Arch Intern Med. 153:2550-2556.

21. Chen F, Kishida T, Yao M, et al. 1995 Germline mutations in the von HippelLindau disease tumor suppressor gene: correlations with phenotype. Hum Mutat. 5:66-75.

22. Maher ER, Yates JRW, Harries R, et al. 1990 Clinical features and natural history of von Hippel-Lindau disease. Q J Med. 77:1151-1163. 